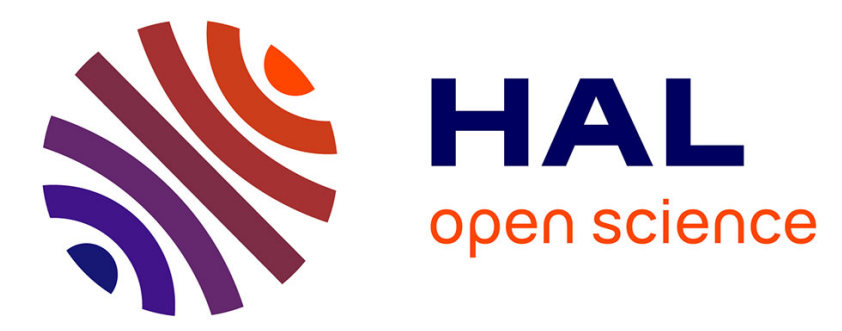

\title{
Hydrogen-induced passivation of boron acceptors in monocrystalline and polycrystalline diamond
}

\author{
Julien Barjon, N. Habka, Jacques Chevallier, François Jomard, E. Chikoidze, \\ Christine Mer, Jean-Charles Arnault, Philippe Bergonzo, Amit Kumar, Julien \\ Pernot, et al.
}

\section{To cite this version:}

Julien Barjon, N. Habka, Jacques Chevallier, François Jomard, E. Chikoidze, et al.. Hydrogen-induced passivation of boron acceptors in monocrystalline and polycrystalline diamond. Physical Chemistry Chemical Physics, 2011, 13 (24), pp.11511-11516. 10.1039/c1cp20303g · hal-00740169

\section{HAL Id: hal-00740169 \\ https://hal.science/hal-00740169}

Submitted on 21 Jan 2022

HAL is a multi-disciplinary open access archive for the deposit and dissemination of scientific research documents, whether they are published or not. The documents may come from teaching and research institutions in France or abroad, or from public or private research centers.
L'archive ouverte pluridisciplinaire HAL, est destinée au dépôt et à la diffusion de documents scientifiques de niveau recherche, publiés ou non, émanant des établissements d'enseignement et de recherche français ou étrangers, des laboratoires publics ou privés.

\section{(ㅇ)(1) $\$$}

Distributed under a Creative Commons Attribution - NonCommerciall 4.0 International 


\title{
Hydrogen-induced passivation of boron acceptors in monocrystalline and polycrystalline diamond
}

\author{
J. Barjon, ${ }^{* a}$ N. Habka, ${ }^{a b}$ J. Chevallier ${ }^{a}{ }^{\text {F. Jomard }},{ }^{a}$ E. Chikoidze, ${ }^{a}$ C. Mer-Calfati, ${ }^{b}$ \\ J. C. Arnault, ${ }^{b}$ P. Bergonzo, ${ }^{b}$ A. Kumar, ${ }^{c}$ J. Pernot ${ }^{c}$ and F. Omnès ${ }^{c}$
}

This paper presents a review of the properties induced by the presence of hydrogen in monocrystalline boron-doped diamond (BDD) and proposes a comparison with results obtained on polycrystalline materials. Hydrogen diffusion, luminescence and electrical properties show the passivation of boron acceptors in diamond by the formation of $(\mathrm{B}, \mathrm{H})$ complexes, in both monocrystalline and polycrystalline forms, but at a different level. This behaviour raises open questions concerning the role of structural defects in the passivation of boron impurities by hydrogenation. Based on the assessment of the high thermal stability of $(\mathrm{B}, \mathrm{H})$ complexes, this approach leads to a route to provide patterned diamond conductive structures for micro as well as for nanotechnology applications.

\section{Introduction}

Diamond is a wide bandgap semiconductor combining ultimate electronic properties (highest hole mobility, saturation velocity and breakdown voltage among all semiconductors) and exceptional physico-chemical properties. For instance, it is exceptionally bio-inert which gives a high compatibility with living tissues in many biological applications, it has one of the largest potential window for electrochemistry in water solution, a remarkable mechanical hardness, a thermal conductivity above that of copper, an unbeaten transparency from ultraviolet to infrared light, a chemical and radiation inertness, etc. Potentially, the panel of applications for this material is extremely wide. ${ }^{1}$ Nevertheless, its synthesis is not straightforward, although rapid progress has been made since the 1980's with the success of chemical vapour deposition (CVD) of diamond materials from either hot filament or microwave plasma enhanced approaches.

In CVD diamond, the effect of hydrogen impurities is a fundamental issue since hydrogen remains the dominant species in the vapour phase (typically $\geq 90 \%$ ) that plays a major role in surface chemical reactions leading to the growth of diamond. ${ }^{2}$ Today, monocrystalline diamond substrates for homoepitaxial growth are commercially available exhibiting dimensions of a few millimetres in size, thus rather restricting their field of application to research on their ultimate properties or to niche-market devices produced in small industrial series.

${ }^{a}$ Groupe d'Etude de la Matière Condensée (GEMaC),

Université Versailles St Quentin and CNRS, $1 \mathrm{pl}$. A. Briand,

92195 Meudon, France.E-mail: julien.barjon@uvsq.fr

${ }^{b}$ CEA, LIST, Diamond Sensors Laboratory,

F-91191 Gif-sur-Yvette, France

${ }^{c}$ Institut NEEL, CNRS and Université Joseph Fourier,

BP166, 38042 Grenoble Cedex 9, France
On the contrary, polycrystalline CVD templates are already available in much larger sizes (up to 4 inches in diameter), and industrial applications are about to develop rapidly. p-type doping is relatively well-controlled today via the addition of boron impurities in the gas phase during diamond growth. Boron introduces an acceptor level at $\sim 0.37 \mathrm{eV}$ above the diamond valence band. ${ }^{3}$ This has motivated a comparison of the hydrogen impurity effects in monocrystalline and polycrystalline boron-doped diamond (BDD).

In high-quality monocrystalline BDD, hydrogen is usually not incorporated at levels above that of traces, and boron is generally not passivated by hydrogen (or only weakly, see e.g., ref. 4 and 27). On the contrary, after a post-growth hydrogenation treatment based on hydrogen diffusion properties, it is known that boron acceptors are mostly passivated by the formation of $(\mathrm{B}, \mathrm{H})$ complexes in monocrystalline diamond. ${ }^{5}$ In the polycrystalline case, we will show that the grain size of polycrystalline diamond is a key parameter in the diffusion properties of hydrogen. As a result, we present the first clear evidences of the electrical passivation of boron acceptors in the case of polycrystalline diamond layers with an average grain size of $50 \mu \mathrm{m}$. Optical and electrical evidences of the boron acceptor passivation will be overviewed for monocrystalline diamond and compared to the case of polycrystalline diamond. Defect engineering based on the physics of $(\mathrm{B}, \mathrm{H})$ formation and dissociation will be discussed with the idea of tuning the BDD diamond electrical properties by hydrogenation post-growth treatments.

\section{Deuterium diffusion in BDD}

a Monocrystalline diamond

Interstitial hydrogen is a donor in p-type diamond. ${ }^{6}$ As a result, it compensates acceptors such as boron, leaving 


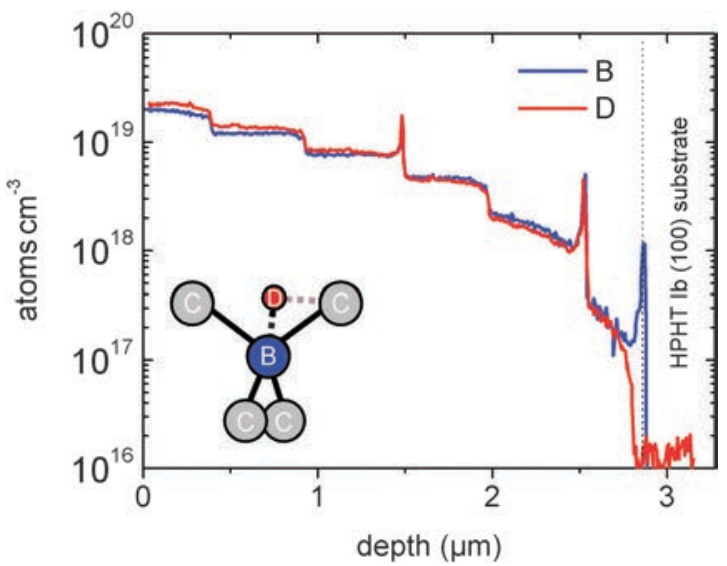

Fig. 1 Deuterium and boron concentration profiles in a BDD monocrystalline multilayer, as obtained by SIMS after exposure to a pure deuterium microwave plasma (details in the text). The $[B] \approx[D]$ equality is verified whatever the level of boron doping, indicating the formation of $(\mathrm{B}, \mathrm{D})$ complexes in the whole thickness of the layer. In the inset, the atomic configuration of the $(\mathrm{B}, \mathrm{D})$ complex is drawn as calculated with $a b$ initio methods. ${ }^{6}$

hydrogen atoms in the charge state $\mathrm{H}^{+}$and compensated boron atoms in the charge state $\mathrm{B}^{-}$. Moreover, a proton $\mathrm{H}^{+}$is highly mobile in diamond, with a migration energy as small as $0.2-0.3 \mathrm{eV}^{6}$ (the lowest for hydrogen in semiconductors). Coulombic attraction combined with fast interstitial diffusion of $\mathrm{H}^{+}$leads to the formation of neutral $(\mathrm{B}, \mathrm{H})^{0}$ complexes via the reaction:

$$
\mathrm{H}^{+}+\mathrm{B}^{-} \leftrightarrow(\mathrm{B}, \mathrm{H})^{0}
$$

For experimental diffusion studies, deuterium is often preferred with respect to hydrogen. It has the same electronic properties with the advantage of being much easily detected using secondary ion mass spectrometry (SIMS) approaches. If the amount of deep traps for deuterium remains below the boron concentration, then the deuterium diffusion is driven by hopping from one boron to another. Deuterium diffusion occurs at temperatures as low as $235^{\circ} \mathrm{C}^{5}$ and is still limited by trapping on boron atoms at $700{ }^{\circ} \mathrm{C} .{ }^{7}$ In SIMS profiles, the formation of $(\mathrm{B}, \mathrm{D})$ complexes is evidenced by $[\mathrm{B}] \approx[\mathrm{D}]$, i.e. the equality of boron and deuterium concentrations in the diamond lattice. This is illustrated in Fig. 1 where a homoepitaxial diamond multilayer with different boron concentrations was exposed to a deuterium microwave plasma at $\left(550{ }^{\circ} \mathrm{C}, 10\right.$ Torr) during $8 \mathrm{~h}$ with a microwave power of $\sim 100 \mathrm{~W}$. The etching of diamond under a deuterium plasma with such a low power density (a few $\mathrm{W} \mathrm{cm}^{-3}$ ) is small. For the sample presented in Fig. 1, an etching rate of $\sim 20 \mathrm{~nm} \mathrm{~h}^{-1}$ was measured by comparing SIMS profiles before and after deuteration.

\section{b Role of the incident deuterium energy}

In a plasma, deuterium species are ionized, and their incident energy plays an important role in the diffusion process. Initially, radio-frequency plasmas were used but in this case, deuterium diffusion profiles exhibit a strong accumulation of deuterium $\left(\sim 10^{21} \mathrm{~cm}^{-3}\right)$ trapped on deep defects in the subsurface region $(\sim 10-50 \mathrm{~nm})$ of diamond. ${ }^{5}$ On the contrary, with the lower incident ion energies of microwave (mw) plasmas, this defective region is absent. ${ }^{19}$ That is the reason why mw plasma are now preferred for deuteration or hydrogenation processes. More recently, the influence of the incident deuterium energy was investigated by polarising monocrystalline BDD layers at different voltages during the mw deuterium plasma exposure. ${ }^{26}$ In these specific experiments, deuterium diffusion by trapping on boron atoms occurs only for voltage values above a threshold of $50 \mathrm{~V}$, which suggests that a minimum incident deuterium ion energy is required to cross the surface diffusion barrier. At high bias voltages $(-200 \mathrm{~V})$, diamond etching occurs with high etching rates $\left(\sim 30 \mu \mathrm{m} \mathrm{h}^{-1}\right)$.

\section{c Polycrystalline diamond}

In polycrystalline diamond, grain boundaries or intragranular defects have long been believed to prevent the formation of (B,D) complexes by acting as deep traps for deuterium. In fact, we have shown in a recent study ${ }^{8}$ that it strongly depends on the size of the involved grains. In polycrystalline diamond with small grains, the diffusion profiles are typical of an irreversible deuterium capture on deep traps, as presented in Fig. 2(a) and as previously reported. ${ }^{23}$ In other words, deuterium migrates to deep traps and remains attached to them without detrapping. On the contrary, when the grain size is large enough $(>50 \mu \mathrm{m})$, we observe the same diffusion mechanism by trapping-detrapping on boron atoms (shallow traps for $\mathrm{H}$ ) as observed in monocrystalline diamond. If the deuterium plasma treatment is long enough, the $[B] \approx[D]$ equality is verified along the whole depth of the layer. ${ }^{8}$ This could open new fields of applications for the physics of (B,D) complexes, which up to now was limited to basic studies on small samples $\left(\mathrm{mm}^{2}\right)$, while nowadays polycrystalline substrates can be commercially available in much larger areas (4 inches).

\section{Luminescence properties of deuterated or hydrogenated BDD}

A signature of the hydrogen-induced boron passivation is clearly observed through excitonic recombinations in cathodoluminescence (CL) experiments. A free exciton (FE) can trap to a neutral acceptor. As a result, in as-grown BDD layers, we observe, in the near-band edge region, the recombinations of both FEs and neutral boron-bound excitons (BE) at a lower energy. Fig. 3 presents such CL spectra for two homoepitaxial samples doped with boron. After a complete deuteration or hydrogenation (i.e. in the whole depth of the layer), the $\mathrm{BE}_{\mathrm{TO}}$ recombination intensity at $5.21 \mathrm{eV}$ decreases dramatically when compared to the $\mathrm{FE}_{\mathrm{TO}}$ intensity at $5.27 \mathrm{eV}$, the TO subscript indicating recombinations assisted by the emission of a transverse optical phonon. The intensity ratio between $\mathrm{BE}_{\mathrm{TO}}$ and $\mathrm{FE}_{\mathrm{TO}}$ is proportional to $\mathrm{Na}^{9}$ As a consequence, it indicates that the boron acceptor concentration $\mathrm{Na}$ is strongly reduced by the formation of (B,D) complexes, i.e. boron acceptors are mostly passivated. 
(a)
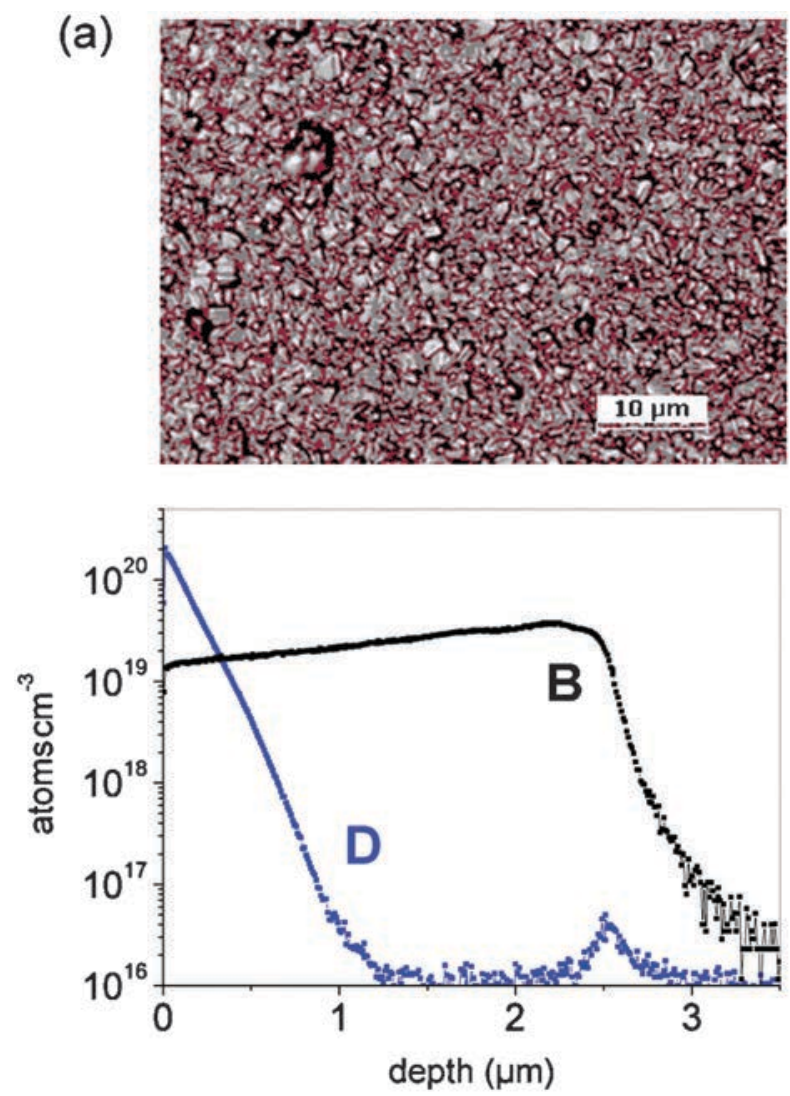

(b)
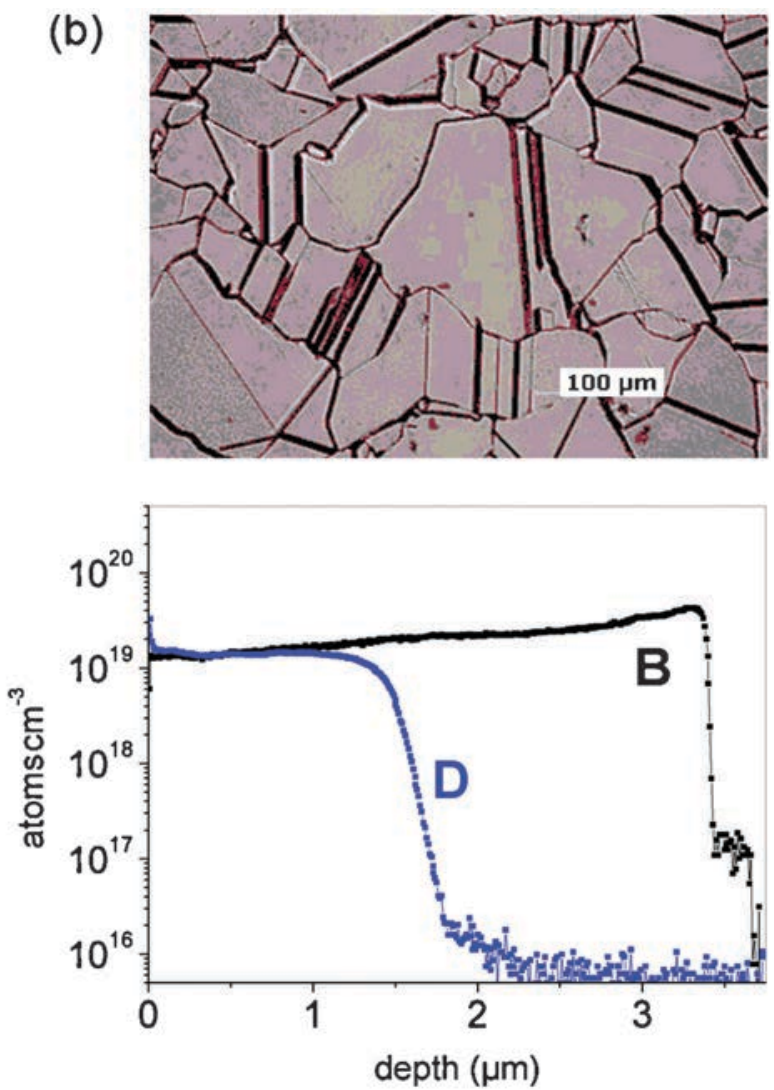

Fig. 2 Deuterium diffusion profiles in polycrystalline BDD exhibiting varying grain sizes. Optical microscope images of the sample surfaces are presented together with the SIMS profiles measured after exposure to a $\left(550{ }^{\circ} \mathrm{C}, 5 \mathrm{~h}\right)$ deuterium microwave plasma treatment in the same conditions. Polycrystalline BDD diamond layers have an average grain size of (a) $0.9 \mu \mathrm{m}$ and (b) $50 \mu \mathrm{m}$ respectively (details in ref. 8).

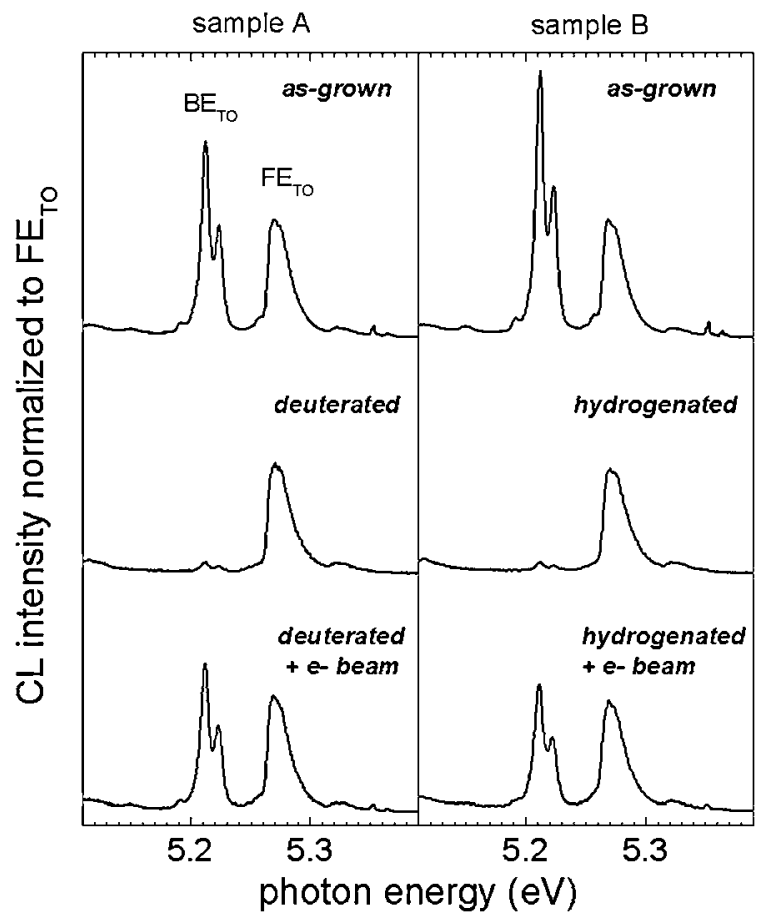

Fig. 3 CL spectra at $102 \mathrm{~K}$ of two boron-doped homoepitaxial layers before (as-grown); after passivation by diffusion of deuterium (sample A) or hydrogen (sample B); after e-beam irradiation of the passivated samples at $(60 \mathrm{nA}, 10 \mathrm{keV})$ during 4 minutes (details in ref. 10).

\section{Electrical properties of deuterated BDD}

\section{a Overview of results in monocrystalline diamond}

To date, the electrical properties of deuterated BDD are yet not fully understood. In the monocrystalline case, after deuteration, a decrease by several orders of magnitude of the hole concentration is usually observed together with an increase of the hole mobility. On one hand, the consequences of deuteration on hole mobilities have been convincingly studied. ${ }^{11,12}$ As a summary, the $(\mathrm{B}, \mathrm{H})$ complex is neutral in p-type diamond at the thermodynamic equilibrium and, as a result, forms a weakly scattering centre for holes. The hole mobility temperature dependence in a deuterated BDD epilayer has been analysed considering either ionized or neutral complexes ${ }^{12}$ using a detailed scattering model. ${ }^{13}$ It shows that the majority of $(\mathrm{B}, \mathrm{H})$ complexes are neutral at the thermodynamic equilibrium in good agreement with $a b$ initio calculations. ${ }^{6,14}$ After the diffusion of deuterium, the material looks as if the acceptor concentration $\mathrm{Na}$ was decreased, leading to the classical mobility increase observed at low doping in semiconductors. If the hole concentration decrease is low, the mobility increase can counterbalance it so that the effect of deuteration on the resistivity may not be dramatic (e.g. the polycrystalline case, in Table 1). In the case of monocrystalline samples, the increase of resistivity after deuterium diffusion is relatively high. As a typical example, an as grown BDD epilayer with $2 \times 10^{19} \mathrm{~B} \mathrm{~cm}^{-3}$ 
Table 1 Electrical transport properties of polycrystalline boron-doped diamond films before and after a deuteration treatment (large-grain sample of Fig. 2(b) with $[\mathrm{B}] \approx 210^{19} \mathrm{~cm}^{-3}$ ). Activation energy $E_{\mathrm{a}}$ and compensation ratios $k=\mathrm{Na} / \mathrm{Nd}$ are deduced from variable-temperature Hall-effect measurements made in GEMaC (ref. 8)

\begin{tabular}{llllll}
\hline & \multicolumn{1}{c}{$T=300 \mathrm{~K}$} & & \\
\cline { 2 - 5 } & Resistivity $/ \Omega \mathrm{cm}$ & Hole concentration $/ \mathrm{cm}^{-3}$ & Hole mobility $/ \mathrm{cm}^{2} \mathrm{~V}^{-1} \mathrm{~s}^{-1}$ & $E_{\mathrm{a}} / \mathrm{eV}$ & $k(\%)$ \\
\hline As-grown & 6.4 & $1.4 \times 10^{16}$ & 70 & 0.18 \\
Deuterated & 26 & $2 \times 10^{15}$ & 120 & 0.25 \\
\hline
\end{tabular}

shows a $0.3 \Omega \mathrm{cm}$ resistivity, while after deuteration it increases to $83 \Omega \mathrm{cm}$ (sample \#3 of ref. 12).

As a consequence, an open issue holds on the passivation ratio $\mathrm{Na} / \mathrm{Na}^{\prime}$ (the prime notation meaning after hydrogenation or deuteration in this paper). It has to be underlined that there are clear difficulties in transport experiments, as they are limited in temperature range due to the thermal stability of hydrogen-related complexes (see section IVa). For instance, the extraction of $\mathrm{Na}^{\prime}$ and $\mathrm{Nd}^{\prime}$ is not possible by variable temperature Hall effect measurements. Only the compensation ratio $\mathrm{Na}^{\prime} / \mathrm{Nd}^{\prime}$ can be reasonably extracted in certain cases. Moreover, it has to be noted that (i) the microstructuration of the test device with lithography and etching (e.g. Hall bars, van der Pauw with mesa, ...) is highly desired to achieve reproducible Hall measurements; ${ }^{15}$ (ii) ohmic contacts on p-type diamond is not straightforward without high temperature annealing (a smart solution may be found in the process developed by Teraji et al. ${ }^{16}$ ). For a better understanding of the passivation ratio resulting from hydrogenation, it is suggested here to combine $\mathrm{C}(\mathrm{V})$ and Hall effect measurements. Preliminary $\mathrm{C}(\mathrm{V})$ results (sample \#1 in ref. 12) already indicate that $\mathrm{Na} /\left(\mathrm{Na}^{\prime}-\mathrm{Nd}^{\prime}\right)$ can be over 20000 in monocrystalline diamond, while the $E_{\mathrm{a}} / 2$ slope in Hall measurements suggests that $\mathrm{Nd}^{\prime} \ll \mathrm{Na}^{\prime}$ i.e. a negligible compensation by residual donors after deuteration.

\section{b In polycrystalline samples}

In the case of the polycrystalline samples with submicrometric grains, there is no clear evidence of the electrical passivation of boron acceptors. But as soon as grains are large enough ( $50 \mu \mathrm{m}$ in average in this work), the same trend as in the case of monocrystalline diamond is observed ( $c f$. Table 1 extracted from ref. 8). After deuteration, the hole concentration decreases and the mobility increases. However, it is remarkable that the value of the compensation ratio $k=\mathrm{Na} / \mathrm{Nd}$ has not evolved much, which indicates a surprising passivation effect on both acceptors and compensating donors. The passivation ratio $\mathrm{Na} / \mathrm{Na}^{\prime}$ can be roughly estimated from the variation of $E_{\mathrm{a}}$ to be around 5, and given the compensation ratios of Table 1 , the passivation ratio $\mathrm{Nd} / \mathrm{Nd}^{\prime}$ to be around 7 .

\section{c Discussion}

The electrical results shown above indicate that passivation occurs on boron acceptors but also on residual donors. Then both the passivation ratio $\mathrm{Na} / \mathrm{Na}^{\prime}$ for acceptors and $\mathrm{Nd} / \mathrm{Nd}^{\prime}$ for donors should be investigated to reach a good understanding of deuterated BDD electrical properties. We have seen previously that the passivation ratio of acceptors $\mathrm{Na} / \mathrm{Na}^{\prime}$ is smaller by several orders of magnitude in polycrystalline diamond when compared to monocrystalline diamond. It suggests that the passivation ratios depend on the structural quality of the material. A competition between shallow boron traps, deep traps (structural defects) and possibly residual compensating donors occurs for the hydrogen trapping. It probably limits the level of boron electrical passivation after hydrogen diffusion. In the same idea, inhomogeneities of passivation ratios have been reported in deuterated homoepitaxial BDD, ${ }^{12}$ and are possibly attributed to HPHT substrate inhomogeneities. The role of structural defects, such as dislocations, stacking faults, grain boundaries, etc., on the passivation ratios appears an open question to understand the electrical properties of deuterated or hydrogenated borondoped diamond.

\section{Prospects}

\section{a Stability of $(\mathrm{B}, \mathrm{H})$ complexes}

In its neutral state the $(\mathrm{B}, \mathrm{H})^{0}$ complex is thermally relatively stable, with a dissociation energy of $2.5 \pm 0.2 \mathrm{eV}$ deduced from experiments $^{7}$ and in good agreement with ab initio calculations. ${ }^{17}$ This makes the $(\mathrm{B}, \mathrm{H})$ pair one of the most stable hydrogendopant complex in semiconductors. For instance, investigations of deuterated BDD by infrared absorption show that the boron acceptor absorptions at $2450 \mathrm{~cm}^{-1}$ and $2800 \mathrm{~cm}^{-1}$ start to recover above $500{ }^{\circ} \mathrm{C}$ after a 2 hours annealing (Fig. 4). This high value suggests that the physics of boron-hydrogen complexes could be exploited in the fabrication of room

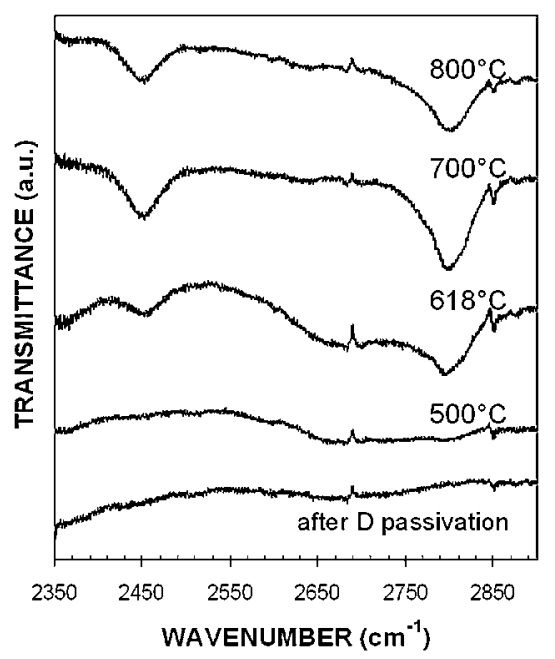

Fig. 4 Recovery of the absorption bands related to the electronic transitions of neutral boron at 2450 and $2800 \mathrm{~cm}^{-1}$ resulting from the dissociation of $(\mathrm{B}, \mathrm{D})$ pairs under successive $2 \mathrm{~h}$ thermal annealings (from ref. 18). 
(a)

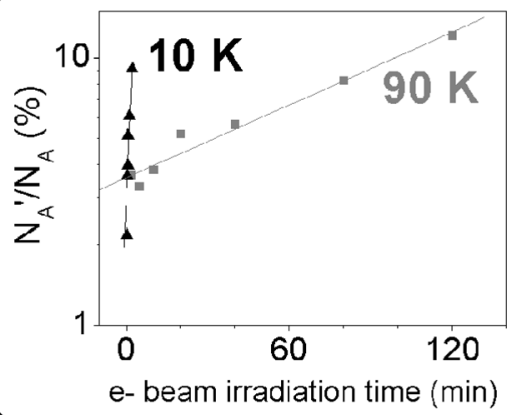

(b)

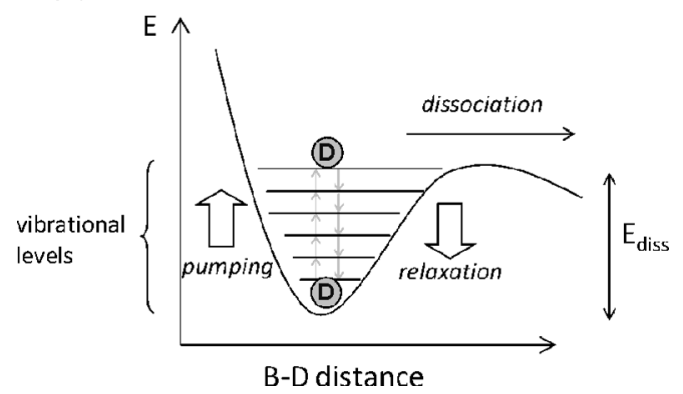

Fig. 5 (a) Fraction of the reactivated boron acceptors under an electron beam as a function of the irradiation time at $10 \mathrm{~K}$ and $90 \mathrm{~K}$; (b) Scheme of the multiple vibrational excitation mechanism. ${ }^{21}$

temperature operating devices, taking care to avoid high temperature processes after the diffusion step.

Another feature can be found in analysing these infrared absorption results. The infrared absorption peaks at $2450 \mathrm{~cm}^{-1}$ and $2800 \mathrm{~cm}^{-1}$ correspond, respectively, to the ground state $\rightarrow$ first excited state electronic transition and to the ground state $\rightarrow$ second excited state electronic transition of the neutral boron acceptors. The absorption intensity is proportional to the net boron acceptor concentration (Na-Nd). In Fig. 4, it is remarkable that $(\mathrm{Na}-\mathrm{Nd})$ almost totally recovers when stopping the isochronal annealing series at $700{ }^{\circ} \mathrm{C}$, temperature which is below the beginning of deuterium out-diffusion from the diamond crystal. ${ }^{19}$ This means that the boron electrical activity is recovered while hydrogen is still trapped at high concentrations inside the diamond lattice. It supposes that the hydrogen atom is released from boron under a form which is electrically inactive, $\mathrm{H}_{2}{ }^{*}$ being a plausible candidate. ${ }^{6}$ This offers perspectives of defect engineering in $\mathrm{BDD}$.

On the other hand, the dissociation energy of $(\mathrm{B}, \mathrm{H})$ pairs is reduced if minority carriers are injected in the material to a value of $0.5-0.7 \mathrm{eV}$ for $(\mathrm{B}, \mathrm{H})^{-}$as calculated by ab initio methods ${ }^{20}$ and in good agreement with the results of dissociation experiments under an electron beam. ${ }^{21}$ Indeed $(\mathrm{B}, \mathrm{H})$ complexes are deep acceptors in p-type diamond as shown theoretically ${ }^{6}$ and with experimental indications. ${ }^{28}$ Under an above bandgap excitation, the $(\mathrm{B}, \mathrm{H})$ complex can become negatively charged with an electron from the carrier bath.

About this effect, it was discovered that under a high current electron beam, $(\mathrm{B}, \mathrm{H})$ and $(\mathrm{B}, \mathrm{D})$ complexes can dissociate at cryogenic temperatures ${ }^{10,22}$ as shown in Fig. 3. It has been proposed that the dissociation occurs when both the following conditions are fulfilled: (i) a reduced dissociation energy due to the injected electron-hole pairs, as already mentioned, and (ii) a cumulative excitation of the $(\mathrm{B}, \mathrm{H})$ local vibrational mode by inelastic electrons as illustrated in Fig. 5(b). Clear signatures of mechanism (ii) are observed through the dependence of the dissociation efficiency on the electron beam current ${ }^{21}$ and in Fig. 5(a) which shows that the dissociation is faster at $10 \mathrm{~K}$ than at $90 \mathrm{~K}$. The local (B,D) dissociation under a focused e-beam could be exploited to write conductive paths in deuterated BDD. The spatial resolution for writing would be limited by a mechanism (ii) which depends a priori on the electron energy losses in the material.

\section{b Micro and nano-electrode arrays}

Considering the possible applications based on $(\mathrm{B}, \mathrm{H})$ defect engineering, localised passivation by hydrogenation through a shadow mask could be a way to fabricate arrays of microelectrodes as presented in Fig. 6. The doping level is laterally modulated, providing atomically flat surfaces with conductive paths at the desired geometry. Such microelectrode arrays
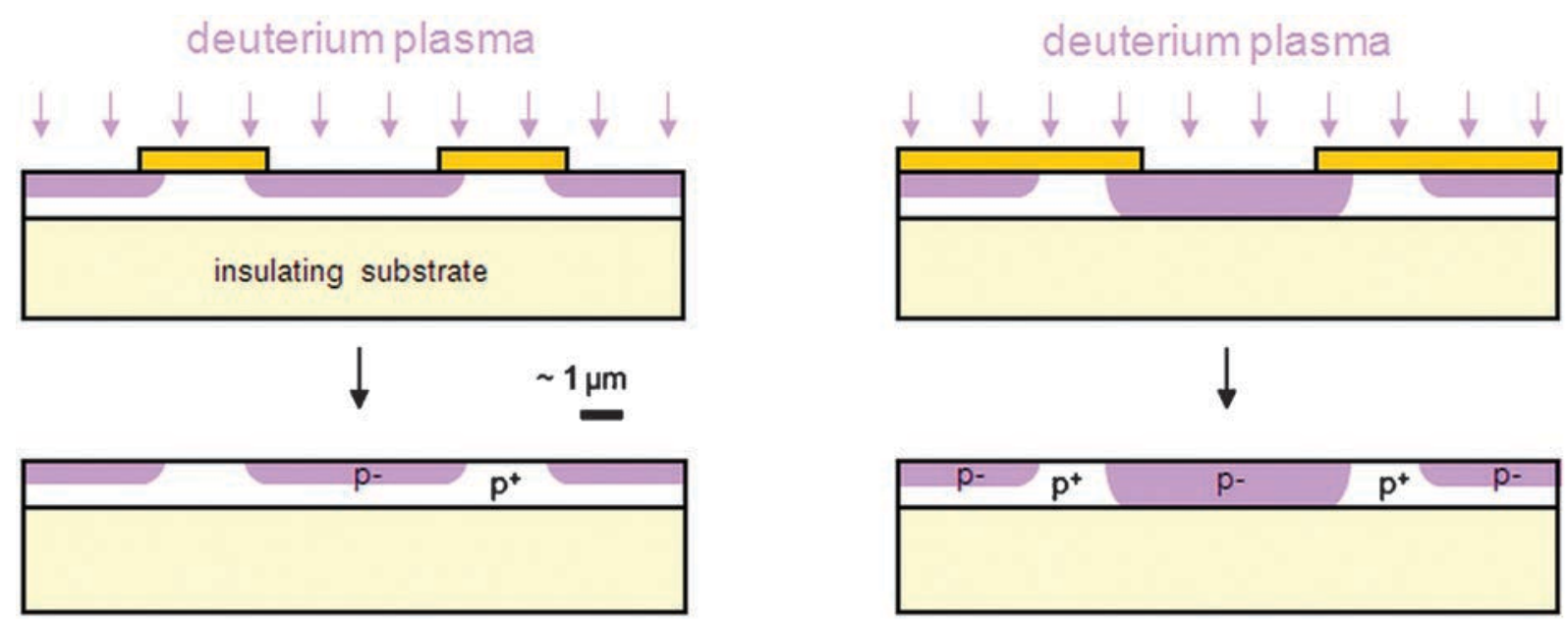

Fig. 6 (a) Localized deuterium-diffusion process through the apertures of a diffusion-blocking mask. Such a process can be used to make interconnected microelectrode arrays, sharing the same electrical potential (b) with a second-step masking, the conductive pathways can be insulated from each other allowing us to electrically address the potential of each conductive area in a $2 \mathrm{D}$ microelectrode array. 
could be interesting for biosensor applications, such as for electrochemical sensors ${ }^{24}$ or for the study of synaptic connections between neuronal cells. ${ }^{25}$ However, in such applications, the resistivity contrast between conductive and insulating areas should be high and well-controlled. These are motivations to answer the basic issues on the electrical properties of deuterated BDD raised in section III.

Finally, (B,D) complexes are both the most thermally stable hydrogen-dopant complexes among semiconductors and dissociable at low temperatures under a focused electron beam. As a consequence, the writing of nanometric conductive pathways on deuterated BDD by an electron beam appears also promising.

\section{Conclusion}

Hydrogen (or deuterium) diffusion occurs by a trappingdetrapping mechanism on boron atoms, leading to the formation of $(\mathrm{B}, \mathrm{H})$ complexes in monocrystalline diamond, as well as in polycrystalline diamond if the grains are large enough. The consecutive passivation of boron acceptors is evidenced by luminescence properties, showing the decrease of $\mathrm{Na}$.

$(\mathrm{B}, \mathrm{H})$ is neutral in $\mathrm{p}$-type diamond as evidenced by electrical measurements and, as a result, forms a weakly scattering centre for holes. It explains why the formation of $(\mathrm{B}, \mathrm{H})$ complexes induces a mobility increase after hydrogenation in BDD. The passivation ratios $\mathrm{Na} / \mathrm{Na}^{\prime}$ and $\mathrm{Nd} / \mathrm{Nd}^{\prime}$ appear much higher in monocrystalline diamond than in polycrystalline diamond, which highlights the role of structural defects. However, a full picture of $\mathrm{Na}^{\prime}$ and $\mathrm{Nd}^{\prime}$ in hydrogenated BDD, and the influence of competing hydrogen traps on these, still lacks today. The high thermal stability of $(\mathrm{B}, \mathrm{H})$ complexes in diamond and their dissociation under a focused electron beam could promote their use in applications, such as for the fabrication of micro or nano-electrode arrays.

\section{Acknowledgements}

This work was financially supported by Agence Nationale pour la Recherche (DOPEN contract ANR 06 BLAN 0339-02).

\section{References}

1 Physics and Applications of CVD Diamond, ed. C. E. Nebel, M. Nesladek and S. Koizumi, Wiley-VCH, Weinheim, 2008.

2 D. G. Goodwin, J. Appl. Phys., 1993, 74, 6888.

3 K. Thonke, Semicond. Sci. Technol., 2003, 18, S20.

4 J. E. Butler, M. W. Geis, K. E. Krohn, J. Lawless Jr, S. Deneault, T. M. Lyszczarz, D. Flechtner and R. Wright, Semicond. Sci. Technol., 2003, 18, S67.

5 J. Chevallier, B. Theys, A. Lusson, C. Grattepain, A. Deneuville and E. Gheeraert, Phys. Rev. B: Condens. Matter Mater. Phys., 1998, 58, 7966.
6 J. P. Goss, R. Jones, M. I. Heggie, C. P. Ewels, P. R. Briddon and S. Öberg, Phys. Rev. B: Condens. Matter Mater. Phys., 2002, 65, 115207.

7 Z. Teukam, D. Ballutaud, F. Jomard, J. Chevallier, M. Bernard and A. Deneuville, Diamond Relat. Mater., 2003, 12, 647.

8 N. Habka, E. Chikoidze, F. Jomard, Y. Dumont, J. Chevallier, J. Barjon, C. Mer and P. Bergonzo, J. Appl. Phys., 2010, 108, 123701 .

9 J. Barjon, T. Tillocher, N. Habka, O. Brinza, J. Achard, R. Issaoui, F. Silva, C. Mer and P. Bergonzo, Phys. Rev. B: Condens. Matter Mater. Phys., 2011, 83, 073201.

10 J. Barjon, A. Mehdaoui, F. Jomard, J. Chevallier, C. Mer M. Nesladek, P. Bergonzo, J. Pernot, F. Omnès and A. Deneuville, Appl. Phys. Lett., 2008, 93, 062108.

11 C. Uzan-Saguy, A. Reznika, C. Cytermann, R. Brener, R. Kalish, E. Bustarret, M. Bernard, A. Deneuville, E. Gheeraert and J. Chevallier, Diamond Relat. Mater., 2001, 10, 453.

12 A. Kumar, J. Pernot, F. Omnès, P. Muret, A. Traoré, L. Magaud, A. Deneuville, N. Habka, J. Barjon, F. Jomard, M. A. Pinault, J. Chevallier, C. Mer-Calfati, J. C. Arnault and P. Bergonzo, J. Appl. Phys., submitted.

13 J. Pernot, P. N. Volpe, F. Omnès, P. Muret, V. Mortet, K. Haenen and T. Teraji, Phys. Rev. B: Condens. Matter Mater. Phys., 2010, 81, 205203.

14 A. Kumar, J. Pernot, A. Deneuville and L. Magaud, Phys. Rev. B: Condens. Matter Mater. Phys., 2008, 78, 235114.

15 N. Yom-Tov, C. Saguy, A. Bolker, R. Kalish and Y. E. Yaish, J. Appl. Phys., 2010, 108, 043711.

16 T. Teraji, S. Koizumi and Y. Koide, J. Appl. Phys., 2008, 104, 016104.

17 J. P. Goss, P. R. Briddon, R. Jones, Z. Teukam, D. Ballutaud, F. Jomard, J. Chevallier, M. Bernard and A. Deneuville, Phys. Rev. B: Condens. Matter Mater. Phys., 2003, 68, 235209.

18 J. Chevallier, A. Lusson, D. Ballutaud, B. Theys, F. Jomard, A. Deneuville, M. Bernard, E. Gheeraert and E. Bustarret, Diamond Relat. Mater., 2001, 10, 399.

19 D. Ballutaud, F. Jomard, J. Le Duigou, B. Theys, J. Chevallier, A. Deneuville and F. Pruvost, Diamond Relat. Mater., 2000, 9, 1171.

20 J. P. Goss and P. R. Briddon, Phys. Rev. B: Condens. Matter Mater. Phys., 2008, 77, 035211.

21 N. Habka, J. Chevallier and J. Barjon, Phys. Rev. B: Condens. Matter Mater. Phys., 2010, 81, 045207.

22 J. Barjon, J. Chevallier, F. Jomard, C. Baron and A. Deneuville, Appl. Phys. Lett., 2006, 89, 232111.

23 D. Ballutaud, A. Boutry-Forveille, J. M. Laroche, N. Simon, H. Girard, M. Herlem and A. Etcheberry, Mater. Res. Soc. Symp. Proc., 2004, 813, 105.

24 C. E. Nebel, B. Rezek and D. Shin, Electrochemical Properties of Undoped Diamond, ed. C. E. Nebel, M. Nesladek and S. Koizumi, Wiley-VCH, Weinheim, 2008, p. 93; C. E. Nebel, B. Rezek, D. Shin, H. Uetsuka and N. Yang, Biosensors from Diamond, ed. C. E. Nebel, M. Nesladek and S. Koizumi, Wiley-VCH, Weinheim, 2008, p. 129.

25 A. Thalhammer, R. J. Edgington, L. A. Cingolani, R. Schoepfer and R. B. Jackman, Biomaterials, 2010, 31, 2097.

26 J. C. Arnault, S. Saada, C. Mer, N. Habka, F. Jomard, J. Barjon and J. Chevallier, Phys. Lett. A, 2010, 374, 3254.

27 C. Fernandez-Lorenzo, D. Araújo, J. Martín, R. Alcántara, J. Navas, M. P. Villar, M. P. Alegre, P. N. Volpe, F. Omnès and E. Bustarret, Diamond Relat. Mater., 2010, 19, 904.

28 T. Kociniewski, Z. Remes, C. Mer, M. Nesladek, N. Habka, J. Barjon, F. Jomard, J. Chevallier, F. Omnès, D. Tromson and P. Bergonzo, Diamond Relat. Mater., 2009, 18, 827. 